This article was downloaded by:[James Cook University]

On: 18 October 2007

Access Details: [subscription number 778407028]

Publisher: Informa Healthcare

Informa Ltd Registered in England and Wales Registered Number: 1072954

Registered office: Mortimer House, 37-41 Mortimer Street, London W1T 3JH, UK

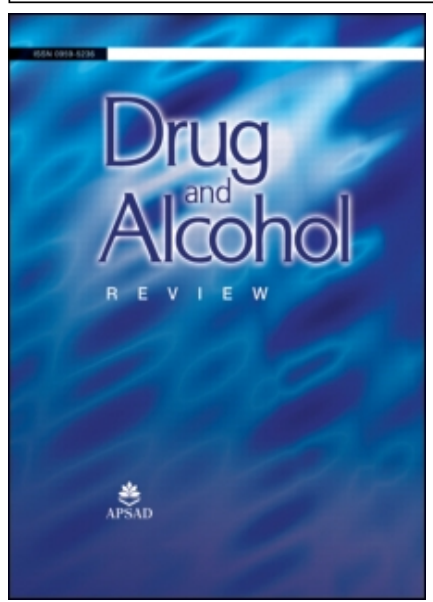

\title{
Drug and Alcohol Review
}

Publication details, including instructions for authors and subscription information: http://www.informaworld.com/smpp/title content=t713412284

Other people, other drugs: the policy response to petrol sniffing among Indigenous Australians

Peter H. D'Abbs ${ }^{\text {ab. Maggie Brady }}{ }^{\text {ab }}$

a School of Public Health and Tropical Medicine, James Cook University, Cairns,

Queensland, Australia

${ }^{b}$ Centre for Aboriginal Economic Policy Research, Australian National University,

Canberra, Australia

Online Publication Date: 01 September 2004

To cite this Article: D'Abbs, Peter H. and Brady, Maggie (2004) 'Other people, other drugs: the policy response to petrol sniffing among Indigenous Australians', Drug and Alcohol Review, 23:3, 253 - 260

To link to this article: DOI: $10.1080 / 09595230412331289400$

URL: http://dx.doi.org/10.1080/09595230412331289400

\section{PLEASE SCROLL DOWN FOR ARTICLE}

Full terms and conditions of use: http://www.informaworld.com/terms-and-conditions-of-access.pdf

This article maybe used for research, teaching and private study purposes. Any substantial or systematic reproduction, re-distribution, re-selling, loan or sub-licensing, systematic supply or distribution in any form to anyone is expressly forbidden.

The publisher does not give any warranty express or implied or make any representation that the contents will be complete or accurate or up to date. The accuracy of any instructions, formulae and drug doses should be independently verified with primary sources. The publisher shall not be liable for any loss, actions, claims, proceedings, demand or costs or damages whatsoever or howsoever caused arising directly or indirectly in connection with or arising out of the use of this material. 


\title{
Other people, other drugs: the policy response to petrol sniffing among Indigenous Australians
}

\author{
PETER H. D’ABBS \& MAGGIE BRADY \\ School of Public Health and Tropical Medicine, fames Cook University (Cairns) and ARC Fellow, Centre for Aboriginal \\ Economic Policy Research (Australian National University), Canberra, Australia
}

\begin{abstract}
This paper examines the policy response of Australian governments to petrol sniffing in Indigenous communities from the 1980s until the present. During this period, despite the formation of numerous inquiries, working parties and intergovernmental committees, there has been little accumulation of knowledge about the nature and causes of sniffing, or about the effectiveness of interventions. Policies are fragmentary; programmes are rarely evaluated, and most rely on short-term funding. The paper sets out to explain why this should be so. It draws upon a conceptual framework known as 'analytics of government' to examine the ways in which petrol sniffing comes to the attention of government agencies and is perceived as an issue; the mechanisms deployed by governments to address petrol sniffing; ways in which knowledge about sniffing is generated; and the underlying assumptions about people that inform policy-making. Drawing upon case studies of policy responses, the paper argues that a number of structural factors combine to marginalize petrol sniffing as an issue, and to encourage reliance on short-term, one-off interventions in place of a sustained policy commitment. Four recommendations are advanced to help overcome these factors: (1) agreements should be reached within and between levels of government on steps to be taken to reduce risk factors before the eruption of petrolsniffing crises; (2) the evidence base relevant to petrol sniffing (and other inhalants) should be improved by funding and directing one or more existing national drug research centres to collate data on inhalant-caused mortality and morbidity, and to conduct or commission research into prevalence patterns, effectiveness of interventions and other gaps in knowledge; (3) the current pattern of short-term, pilot and project funding should be replaced with longer-term, evidence-based interventions that address the multiple risk and protective factors present in communities; and (4) insistence by governments that communities must take 'ownership' of the problem should be replaced by a commitment to genuine partnerships involving governments, non-government and community sectors. [d'Abbs P, Brady M. Other people, other drugs: the policy response to petrol sniffing among Indigenous Australians. Drug Alcohol Rev 2004;23:253-260]
\end{abstract}

Key words: drug policy, Indigenous health, inhalants, petrol sniffing, volatile substances.

\section{Introduction}

The focus of this paper is not petrol sniffing itself, but the responses of Australian governments-state, territory and commonwealth-to petrol sniffing since its emergence in a number of remote Indigenous communities in the 1960s. Throughout the 1980s, governments established numerous working parties, task forces and interdepartmental committees, as well as a Senate inquiry, in a search for appropriate policies [1 5]. The following decade saw fewer high-level inquiries, and a trend towards Commonwealth funding for community-based initiatives such as Petrol Link-up in Central Australia [6]. Most funding was short term, and initiatives were rarely evaluated. More recent policy interventions include a Commonwealth scheme to subsidize use of aviation fuel as a substitute for petrol in remote communities, and a one-off allocation of $\$ 1$ million to programmes in the Northern Territory, initiated by the Prime Minister in 2001 [7].

Yet despite these efforts, the situation today differs little from that of 30 years ago. As several recent inquiries point out, there are still practically no policies at any levels of government [8,9], nor is there an accumulated body of knowledge about the nature and causes of sniffing or about the efficacy or effectiveness of interventions. Most initiatives continue to rely on short-term project funding [10].

Peter H. d'Abbs PhD, School of Public Health and Tropical Medicine, James Cook University, PO Box 6811, Cairns, Queensland 4870, Australia; Maggie Brady PhD, ARC Fellow, Centre for Aboriginal Economic Policy Research (Australian National University), Canberra, Australia. Correspondence to Dr Peter d'Abbs, School of Public Health and Tropical Medicine, James Cook University, PO Box 6811, Cairns, Queensland 4870, Australia. E-mail: Peter.Dabbs@jcu.edu.au

Received 16 October 2003; accepted for publication 5 February 2004.

ISSN 0959-5236 print/ISSN 1465-3362 online/04/030253-08 (C) Australian Professional Society on Alcohol and Other Drugs DOI: $10.1080 / 09595230412331289400$ 
Why should this be so? In this paper we attempt to answer this question. We argue that the processes by which petrol sniffing periodically gains a place on the policy agenda, and the ways in which petrol sniffing is construed as a policy issue, both mitigate against the development of sustained, evidence-based policies and programems.

\section{A conceptual framework: governance and the construction of problems}

The conceptual framework underpinning our analysis draws upon Dean's 'analytics of government' [11]. Dean defines government to include 'any attempt to shape with some degree of deliberation aspects of our behaviour according to particular sets of norms and for a variety of ends' [11]. Governing, in this sense, is a set of activities undertaken by a broad range of agencies over and above those recognized as 'the government'. In the case of indigenous petrol sniffing, the list includes:

- politicians acting as individual politicians, at all levels of government (including indigenous community councils);

- politicians acting collectively as 'the government' - again, at all three levels of government;

- bureaucratic agencies, especially in the domains of health, education, sports and recreation, and law enforcement-and, in recent years, coroners' courts; and

- advisory bodies such as the National Drug Strategy Aboriginal and Torres Strait Islander Reference Group.

Outside the government sector, other agencies that periodically seek to influence behaviour related to petrol sniffing include:

- non-government organizations that manage petrol sniffing intervention programmes;

- large international bodies such as UNICEF and WorldVision;

- the media;

- researchers and consultants; and

- multi-national corporations, especially petrol producers such as BP.

Dean identifies four key dimensions of government, as follows:

(i) 'fields of visibility': the ways in which phenomena are envisaged by agencies of government;

(ii) technical aspects of government, i.e. the 'means, mechanisms, procedures, instruments, tactics, techniques, technologies and vocabul- aries' by means of which agencies of government act;

(iii) forms of knowledge and expertise employed in governing; and

(iv) the 'formation of identities' - that is 'the forms of individual and collective identity' that governments recognize and try to promote [11, p. 32].

In this paper, we examine petrol sniffing with respect to all four dimensions, with particular attention on the first three.

\section{Petrol sniffing as a 'field of visibility'}

How does petrol sniffing in Indigenous communities become visible among all the other issues competing for policy makers' attention? Usually, it does so by erupting periodically into the living rooms of the public through highly sensational media exposés, redolent with images and stories evoking senseless tragedy, and personal and community crisis. 'Sniffing at death' shouted the front page of the Adelaide Advertiser's Saturday Review of 29 December 1984, in a story featuring close-up photographs of (identifiable) Aboriginal children in the Pitjantjatjara lands with containers of petrol to their noses [12]. Sixteen years later, the Sydney Morning Herald and The Age showed colour photographs of young Aboriginal boys sniffing petrol under the banner 'Deadly visions of the desert children' [13] and 'Desert visions turn deadly' [14]. The boys were easily identifiable, as was the method of inhalation. (The captions also contained an unfortunate double entendre, in that the word 'deadly' in Indigenous youth argot carries positive connotations of 'coolness'.) Paul Toohey's article headed 'A generation stolen by the fumes' (15) appeared 2 weeks later in the UK Sunday Telegraph under the headline 'Babies hooked on petrol fumes' [16].

The media portrayal of Aboriginal petrol sniffing is worthy of a study in its own right; in particular, one might ask why acts of petrol sniffing are represented implicitly not merely as instances of individual selfharm, but as evidence of a broader community disintegration in a way that heroin use, for example, is never portrayed.

Another salient characteristic of petrol sniffing as an issue is the absence of any lobby groups or other agencies with the capacity to keep the issue on the public agenda in anything more than a transient manner. Kingdon, in his study of policy making in the United States, notes that issues gain a place on the public agenda by being transformed from 'conditions' to 'problems' [17]. This can happen by a variety of processes: statistics, for example, might be cited to 
draw attention to a disturbing trend, such as the increase in obesity in Australia, or an issue might be the subject of sustained lobbying by interest groups, as domestic violence was gradually forced onto the policy agenda in the 1970s. Petrol sniffing, by contrast, is a product of neither statistical trends nor sustained lobbying; as a public issue, it owes almost everything to media outbursts (although in recent years at least two coronial inquests have drawn attention to the issue in a way that might yet generate pressures for change).

One result is that whatever pressure for action that emerges is usually for a quick, short-term response. Often it comes from individual politicians, who are either genuinely moved by the media accounts, or do not wish to be seen as unresponsive. Because petrol sniffing is seen in the first instance as destroying the health of sniffers, this pressure falls initially on agencies in the health sector.

In responding, however, health bureaucracies face other constraints. Experiences gained by one of us (Pd'A) suggest that at least five sets of factors dictate priorities. First, bureaucrats have to manage budgets, usually tight budgets. Consequently, they will pay attention to problems that threaten to blow out budgets. Secondly, while bureaucrats are bound to heed the political directives of the government of the day, the extent to which they also respond to political pressures emanating from elsewhere is more open to discretion. Thirdly, health agencies attend to major sources of morbidity and mortality. This third factor tends to interact with a fourth: perceived efficacy and effectiveness of available interventions. That is to say, health bureaucracies, like other agencies, prefer to direct limited resources where they can reasonably hope to achieve results and, conversely, to limit allocation where they see little prospect of results, sometimes by attempting to redefine an issue as someone else's problem. Finally, health bureaucracies tend to be preoccupied with issues and problems that threaten their capacity to maintain a stable, qualified work-force.

How is petrol sniffing among Indigenous people perceived within this context? First, it does not generate the pressure on limited budgets with which bureaucrats must deal on a day-to-day basis, except perhaps in the case of a small number of sniffers and ex-sniffers who suffer permanent and serious disabilities. Nor is petrol sniffing a major contributor to indigenous morbidity or mortality. Alongside the harm wrought by chronic diseases, alcohol-related violence and tobacco use, it is barely visible. Further, the tools available to the health sector for responding to petrol sniffing - such as health promotion and guidance in clinical management of sniffers-are of limited efficacy. Finally, petrol sniffing in communities rarely generates problems in recruiting and retaining staff (unlike, for instance, alcohol-related hostility towards health-centre staff).
There are, in short, any number of reasons why health bureaucracies should be preoccupied at any given time by issues more pressing than petrol sniffing in remote communities. In effect, they are in a crossfire: pressured from outside by the media and/or particular politicians to act in response to a problem that is not, from where they sit, among their most critical challenges. This situation tends to have three consequences: first, while the agencies will take some sort of action, they will try to avoid diverting resources from other areas that are seen as ongoing priorities, or that are seen as representing better returns on expenditure. Secondly, the desire to refocus on what are seen internally as more important issues creates an incentive to make a visible gesture - such as funding a non-government organization to conduct a one-off project - and then return to the main game. Thirdly, the agency is unlikely to harbour a section or even a network of individuals with an ongoing interest in keeping petrol sniffing high on the agenda of priorities. As one experienced public servant in the Northern Territory, interviewed for this study, put it: 'As soon as you raise the issue of petrol sniffing in the public service, people duck for cover. They go on leave. They disappear.'

In short, health bureaucracies are structurally motivated to take short-term action that is unlikely to be informed by a constituency of expertise, either internal or external. If policy of any sort emerges, it will probably be what another public servant, this time with the Commonwealth, described as 'policy on the run'.

To the extent that it does command bureaucratic attention, the way in which petrol sniffing is conceptualized is shaped by two further factors: first, it is viewed as an instance of inhalant misuse or volatile substance misuse, which in turn is framed within a broader discourse of substance misuse. Secondly, it is seen as an Indigenous issue. We consider briefly the implications.

Within discourses of substance misuse, inhalants occupy a marginal position. To begin with, they do not fit neatly into a licit/illicit drug taxonomy. Usually they are categorized in a residual 'other drugs' category, where they may or may not be distinguished further as petrol sniffing, glue sniffing, chroming etc. Secondly, the key concepts and theories that inform drug abusesuch as dependency and withdrawal - are of questionable value in addressing what is, after all, a pattern of behaviour grounded clearly in social and economic disadvantage.

Petrol sniffing among Indigenous Australians is all but invisible in contemporary drug policy. The National Drug Strategic Framework 1998-99 to 2002-03 makes just two references to the issue, the first to inform readers that the 'proportion of Indigenous Australians who had used inhalants or kava in the 
12 months preceding the survey could not be reliably estimated' [18, p. 5], the second to highlight the dangers:

Petrol sniffing is one of the most dangerous forms of inhalant use and prolonged sniffing can lead to longterm disability. The behaviours associated with inhalant use and the long-term care of people who use inhalants can be extremely distressing, disruptive and debilitating for the families and communities involved $[18$, p. 10].

Similarly, the National Action Plan on Illicit Drugs 2001 to $2002-03$ skirts around inhalants by stating that they would be covered in a separate complementary strategy to be prepared for Aboriginal and Torres Strait Islander drug use issues [19]. A background paper accompanying the National Action Plan includes a section headed 'Illicit drug use among Aboriginal and Torres Strait Islander peoples' which makes no reference to inhalants, volatile substances or petrol sniffing [20]. Finally, Fitzgerald and Seward's recent study of drug policy in Australia, published by the Australian National Council on Drugs, makes no reference to petrol sniffing, volatile substances or inhalants [21].

The Aboriginal and Torres Strait Islander Peoples' Complementary Action Plan, released in August 2003, makes four proposals in relation to volatile substance misuse:

- encourage exchange among communities of strategies to reduce harm associated with volatile substances (e.g. night patrols, aviation fuel);

- enforce penalties for inappropriate sales of volatile substances and tobacco;

- develop community education resources as well as targeted educational resources for selected groups such as parents; and

- support communities to conduct action research on early intervention among inhalant users [22].

Petrol sniffing's marginal status can be traced at least to the origins of Australia's current national drug policy in the 1985 National Campaign Against Drug Abuse (NCADA). NCADA's initial focus was on illicit drugs, alcohol and tobacco. Petrol sniffing was not a priority. One of the earliest publications released by NCADAentitled An Australian Guide to Drug Issues-noted inhalants as 'other' [23]. One of us (MB) recalls phoning the NCADA office at about this time to ask about resources on petrol sniffing, only to be told that petrol was not part of NCADA 'because it was Aborigines'!

This bizarre response testifies to the influence of the second factor mentioned above. At the time of
NCADA's formation Aboriginal affairs had become in effect quarantined from the major thrust of national policy-making and analysis. Indigenous health matters were dealt with by the Department of Aboriginal Affairs (DAA), and later by the Aboriginal and Torres Strait Islander Commision (ATSIC), neither of which was linked bureaucratically to the health department, but reported instead to it's own minister. Documents produced by these agencies, such as the National Aboriginal Health Strategy [24], frequently stressed cultural difference and the 'special case' of Aborigines. Not surprisingly, an evaluation of the first 3 years of NCADA found that Aboriginal people had derived little benefit from the campaign [25].

In 1995, responsibility for administering Commonwealth funds for Aboriginal alcohol and other drug programmes was transferred back to the mainstream health bureaucracy. However, the ideas within which these programmes were framed remained outside mainstream alcohol and other drugs discourses, being derived instead from a contemporary Aboriginal policy framework. In remote regions, this was characterized by what O'Malley has termed 'governing at a distance' [26]. In place of the pervasive regulation of Aboriginal life in administered settlements, as had occurred during the assimilationist policies of the 1950s and 1960s, governance was based on enlisting Indigenous forms of social organization and control-or, rather, what agencies of the state perceived to be Indigenous forms - to manage Indigenous behaviour. The purpose was no longer tutelage for full citizenship in a monocultural Australia but rather the fostering of selfdetermining subjects who would be enriched and empowered through their own Indigenous cultural traditions.

The new policy was part of a broader shift in the principles of governance initiated at the time throughout many liberal democracies, away from governance through centralized regulation, towards more decentralized, indirect forms of social control, aimed at fostering self-regulating consumers ready to take their place in a competitive society. Central to these changes in the domain of governing Indigenous Australians has been the strategy of enlisting 'communities' [26]. Aboriginal communities are expected to articulate aspirations which are then taken as authentic manifestations of 'self-determination'-as long as they accord more or less with what the state wants them to choose. In an acerbic account of these processes in one Northern Territory locality, Cowlishaw describes four stratagems by means of which government bureaucrats deal with discrepancies between 'communities' as ideologically defined and the observed reality in front of them. The first is through endless meetings, at which officials purport to obtain the agreement of 'the community' to appropriate decisions. The second she 
calls 'ventriloquism': the practice of white officials concealing their own role in decision-making by claiming that decisions have been taken by Aboriginal people. The third is the use of a notion of 'culture' that purports to represent Aboriginal tradition but that, Cowlishaw argues, is neither informed by nor recognizes the multi-faceted, interwoven strands of Indigenous sociality. The fourth is the attempt to define separate private and public spheres in which 'the community', far from representing a pre-existing, Indigenous social entity, is construed as a public space which then becomes the legitimate domain of government-supported programs [27].

In one sense, then, communities are the creations of the state, designed to facilitate the purposes of the state in accord with the principles of contemporary governance in an advanced liberal society. Among these purposes is the assumption of primary responsibility for preventing and responding to petrol sniffing - not to mention a host of other issues. Perhaps the crudest statement of community responsibility for petrol sniffing was a comment made by then Aboriginal Affairs Minister Clyde Holding in 1984. Challenged by a national Aboriginal child care agency to provide $\$ 5$ million to address petrol sniffing, $\$ 2.5$ million of which was to be used to assist communities in north-western South Australia, Holding retorted: 'The communities just opt out and say all that is needed to solve the problem is $\$ 2.5$ million. Why $\$ 2.5$ ? Why not $\$ 20$ million? How much money do you need to take a petrol can from a kid when you see him sniffing in front of you? Let's address this problem in real terms' [12].

A few observers have long questioned the wisdom of this 'hands-off' approach by government. In 1977 a Northern Territory Welfare Officer wrote:

I do not agree with the very common attitude that because these are problems of the Aboriginal people that they [the Aboriginals] have to find the answers. I see this as an excuse by the authorities responsible to abdicate that responsibility and involvement; and they do it under the very admirable guise of 'selfdetermination' (G. Sargent cited in [28, p. 125]).

Aboriginal people have been even more forthright. Kawaki Thompson, father of a young man from Central Australia who died from sniffing petrol, told a recent coronial inquiry:

There has been petrol sniffing since the 1950s. Who is responsible? The petrol doesn't belong to us. It is not part of Anangu law. It was introduced to the Lands by white people. It is important that Anangu revive their culture and hold on to their culture. The problem with petrol comes from outside, it's like the
Maralinga bomb tests, the solution should come from the outside too [9, Thompson report, p. 19].

Such views, however, have had little impact on policy. A strategy outlined by the Department of Aboriginal Affairs in 1987 drew on an earlier Senate inquiry to state in its opening paragraph that 'actions in response to petrol sniffing should originate from and be controlled by the Aboriginal people in each community where petrol sniffing is a problem' [2, Attachment G]. The Department's role was to 'act as a resource to encourage and support community initiatives'.

Ironically, the Department's own deliberations exposed the problematic nature of this position. At a petrol sniffing conference held in Perth in September 1987, those present agreed that petrol sniffing resulted primarily from 'disempowerment of the people and erosion of their own forms of authority', and that petrol sniffing 'was a symptom of a process of social deterioration rather than the focal problem itself' [2].

In 2003, the question remained unanswered by governments. As Dr Paul Torzillo, a respiratory physician with long-term experience in central Australian communities, told a coronial inquiry held in 2002 into the deaths of three petrol sniffers:

There seems to be a widespread view within government...that this is a problem which the community should solve, it is their responsibility. This is a community with less resources and ability to control a tough problem than any mainstream community... and secondly, that's not a demand that's put on any other community in the country. No-one, no politician and no bureaucracy expects that a suburb like - so the people of Cabramatta are not told that they have to solve the heroin problem and it's up to them to do it [9, Thompson report, $p$. 20].

Coroner Chivell agreed: 'Governments', he insisted in his findings, 'should not approach the task on the basis that the solutions must come from Anangu communities alone' [9, Thompson report, p. 74].

Together, these structural constraints and discursive frameworks have shaped the responses of various governments to Aboriginal petrol sniffing over the past three decades, in ways that we shall now briefly consider.

\section{Petrol sniffing and techniques of government}

In a review of interventions into petrol sniffing, d'Abbs \& MacLean [29] identified a large number of programmes, including in the area of primary prevention, recreation programmes, education, substitution of petrol with aviation fuel, locking up petrol supplies, 
adding deterrents to petrol, movements to homelands centres and legal sanctions against sniffing, and use of Aboriginal culture and symbolism. Interventions targeting at-risk or user populations include individual and family counselling, community wardens and night patrols and guidance in harm minimization. Finally, in the area of tertiary intervention, both hospital treatment and residential rehabilitation programmes have been utilized.

We do not discuss these measures here. Those seeking further information are referred to the monograph itself, or to a shorter journal article summarizing the main findings [30]. Instead, we wish to highlight a number of characteristics of prevailing approaches to interventions. First, because petrol sniffing is not seen as a genuine ongoing priority issue that falls neatly into any one department's or even one government's scope of responsibility, governments have tended not to engage in direct service provision, but rather to fund community-based groups and other non-government organizations to provide services. This, of course, also accords with the view of petrol sniffing as a community responsibility. Secondly, and again in light of petrol sniffing's low priority, most initiatives have been funded on an ad hoc, short-term basis, with virtually no commitment to rigorous evaluation or to providing ongoing funding to those programmes that demonstrate successful outcomes. Thirdly, because so few programmes are evaluated, and because no one sector in any bureaucracy has an interest in maintaining sustained attention on the problem, the efforts that have been made have not generated an evidence base that might inform future policy-making and programme funding. (A welcome exception to this pattern is the decision to evaluate the 'Comgas' scheme. This is a subsidy introduced in 1998 under which the Commonwealth meets the cost of excise duty on aviation fuel, used in some communities as a harm minimization device and alternative to petrol.) Fourthly, in the absence of an evidence base, and because petrol sniffing straddles political jurisdictions as well as departmental 'silos', governments have tended to respond to petrol sniffing crises by convening high-level inter-governmental committees involving commonwealth and state/ territory officials. In no instances to date, however, have these committees succeeded in implementing a coordinated, sustained approach to the prevention or treatment of sniffing.

The reasons for these repeated failures lie, we suggest, in the factors we have outlined above. Coroner Chivell, commenting on the most recent of these committees-namely, the South Australian Government's Anangu Pitjantjatjara Lands Inter-Governmental Inter-Agency Collaboration Committee and the Commonwealth-administered Central Australian Cross Border Reference Group-remarked caustically that both seemed to be stuck in the 'information gathering' phase, and added: 'There is no need for further information gathering, and there is a vast untapped pool of professional expertise to be utilised. What is missing is prompt, forthright, properly planned, properly funded action' [9, Thompson report, p. 34].

\section{Knowledge, expertise and petrol sniffing}

Is there, as Chivell asserts, 'a vast untapped pool of professional expertise to be utilised'? In making these comments, Chivell rightly condemns bureaucratic inertia and dismisses the claim that we cannot act because of lack of information. At the inquiry, the coroner heard claims that considerable research had already been conducted into petrol sniffing, and that lack of knowledge was not a legitimate barrier to action. At the same time, Chivell himself concluded that, as a phenomenon, petrol sniffing remained poorly understood [9].

What are we to make of this apparent paradox? In the face of governments' apparent unwillingness to act, any exercise in data-gathering in the name of research can constitute self-serving indulgence. However, if research and the knowledge it generates are never sufficient conditions for coherent policies and programmes, they are necessary conditions, and if we compare petrol sniffing with other categories of substance misuse, 'the vast untapped pool of professional expertise' looks somewhat shallower than Chivell implies.

Effective targeted policies and interventions require at least three kinds of knowledge: first, epidemiological data about prevalence patterns, distribution and correlations with other phenomena of interest; secondly, knowledge about the efficacy and effectiveness of interventions and factors that influence effectiveness; and thirdly, knowledge about the ways in which inhalants affect physical and mental functioning. While a limited amount of research into all of these areas has been conducted, both in Australia and overseas, petrol sniffing has attracted relatively little research attention. For example, the two leading drug research institutes in Australia are the National Drug and Alcohol Research Centre (NDARC), attached to the University of New South Wales, and the Perth-based National Drug Research Institute (NDRI), attached to Curtin University of Technology. The former is orientated towards treatment-related research, the latter towards prevention research. A search of NDARC's publications list of several hundred journal articles, monographs and technical reports, as listed on their website [http:// ndarc.med.unsw.edu.au/ndarc.nsf/website/Publications.articles], failed to reveal a single publication focusing on petrol sniffing, inhalants or volatile substances. A similar publications search on NDRI's website found one evaluation report published in 1989 [31] and one 
letter published in the Medical fournal of Australia in 1993 [32]. This is not to suggest that aspects of petrol sniffing or other volatile substance use are not covered in other publications from these centres, as part of, for instance, overviews of trends in drug use patterns; but the near total absence of any publications that feature inhalants is a telling indicator of the place that inhalants occupy in mainstream drug research in Australia. Moreover, as the earlier quotation from the National Drug Strategic Framework implied, petrol sniffing in Indigenous communities is rarely captured in national drug use surveys, in part because samples are usually drawn from people aged 14 or 15 years and over, thereby excluding many sniffers, and in part because the restriction of sniffing to isolated geographical locations and its episodic nature render it invisible in all but the largest samples.

In short, the lack of any sustained institutional interest in petrol sniffing among government agencies is matched by a dearth of high quality research.

\section{Petrol sniffing and the formation of identities}

The final dimension of 'governance' being considered here has received less attention than the other three: it refers to the assumptions made by governing agencies about the kinds of people they are dealing with and the kinds of people they strive to foster. O'Malley argues that contemporary governance of Indigenous people in Australia-in parallel with non-Indigenous governance-seeks to promote what he has labelled 'selfdetermining subjects of liberalism' [26, p. 168]. We do not elaborate the point here, but it could be argued that petrol sniffing-especially as it is usually portrayed in the media-represents an all-too-literal 'in your face' affront to this goal, in that it exposes the fallacy behind the notion that disempowered people who are trapped in poverty will play the part that contemporary governance holds out for them.

\section{Where to now?}

In sum, petrol sniffing in Indigenous communities appears episodically on the public policy agenda thanks mainly to (often sensational) media accounts; unsupported by any sustained lobbying, however, the issue vanishes almost as quickly as it appears. From the vantage point of government bureaucracies, it tends to be crowded out by other, more pressing issues. As a policy issue, it tends to fall between levels of government and, within levels, between departmental 'silos'. Within discourses of drug treatment and policy, petrol sniffing - along with inhalants generally-is marginalized further. Finally, government responses have been shaped by a policy discourse in which Aboriginal 'selfdetermination' has been conflated with notions of 'community responsibility' in a manner that pays no heed to the capacities or resources available to most communities.

The implications of our analysis are, we suggest, sobering: none of the factors outlined in this paper lend themselves readily to modification. However much we might wish it otherwise, petrol sniffing in remote Aboriginal communities is not likely to become a long-term policy priority, given the presence of so many competing claims on attention and resources. So what should be done? We propose four modest, practical steps that could usefully be taken to improve the policy foundation without imposing a major demand on resources. First, it must be possible-especially in an environment where so many agencies claim to espouse a 'whole of government' approach - for agreement to be reached between relevant departments at one level of government, and between levels of government, on a series of steps to be taken to reduce risk factors before the eruption of yet another media-generated crisis. For example, it has long been known-but it still needs to be said-that youth workers and appropriately trained and supported recreation officers have a major contribution to make in the prevention of inhalant abuse. A coordinated approach to the provision of these resources, based on systematically reducing risk factors in inhalant-prone environments, should be implemented. Secondly, the evidence base relevant to petrol sniffing (and other inhalants) could be increased by utilizing one or more of the existing national drug research centres. These centres should be funded and directed to conduct or commission research into prevalence patterns, effectiveness of interventions and other current gaps in knowledge, and to publish regular bulletins of national data on inhalant-caused deaths and hospitalizations, similar to the National Alcohol Indicators Bulletins published by the National Drug Research Institute. This would serve to encourage better compilation of coronial data from different jurisdictions, highlight the difficulties in collating such data and provide the basis of a formal nationwide collection of statistics on the impact of petrol sniffing and other inhalants on morbidity and mortality. Thirdly, petrol sniffing is too complex an issue to be addressed through short-term pilot and project funding; it requires, rather, longer-term interventions that address the multiple risk and protective factors present in communities, and that build upon programmes that have been shown to be effective. Finally, while communities must be partners in any programme to address petrol sniffing, the notion that government agencies can sit back and insist that communities take 'ownership' of the problem, and that all governments need to do is provide intermittent project grants to community groups, needs to be exposed and rejected. A genuine partnership approach involving government, 
non-government and community sectors, committed to collating, utilizing and building on evidence of effectiveness, has the potential to reduce significantly the present tragic waste of personal and community opportunities wrought by petrol sniffing.

\section{Acknowledgements}

This work is a revised version of a paper presented at Australian Institute of Criminology Conference 'Inhalant Use and Disorder', Townsville, Queensland, $7-8$ July 2003. The research reported here is work in progress under National Health and Medical Research Council Project Grant 193317 entitled 'The Policy Response to Indigenous Petrol Sniffing - and How to Improve It'. The authors would like to thank three anonymous reviewers whose suggestions have, we believed, improved the paper, although responsibility for any errors remains with the authors.

\section{References}

[1] Anon. Working party formed: Ministers act on petrol sniffing. West Australian, 1 March 1982.

[2] Department of Aboriginal Affairs. Report, Petrol Sniffing Conference, Perth, WA, 30 September 1987. Perth: Department of Aboriginal Affairs, 1987.

[3] Senate Select Committee on Volatile Substance Fumes. Volatile substance abuse in Australia. Canberra: Australian Government Publishing Services, 1985.

[4] Robbins J. Volatile substances: coordinating petrol-sniffing programs for Aboriginal communities in a federal system. Aust J Public Admin 1993;52:65-74.

[5] Willoughby P. Special force to combat petrol sniffing. Advertiser, 8 November 1986, p. 4.

[6] Shaw G, Armstrong W, San Roque C. Petrol link up: interim report stage 1, March-July 1994. Canberra: Australian Government Publishing Service, 1995.

[7] Taylor J. The world today archive: PM announces funds to fight petrol sniffing. 20 February 2001 [ABC Online www.abc.net.au/worldtoday/s249140.htm 2001].

[8] Parliament of Victoria Drugs and Crime Prevention Committee. Inquiry into the inhalation of volatile substances: final report. Melbourne: Government Printer for the State of Victoria, 2002.

[9] Chivell WC. Finding of Inquest at Umuwa, South Australia, in May, June and September 2002 into three deaths. Adelaide: South Australian Coroner's Office, 2002.

[10] d'Abbs P, MacLean S. Petrol sniffing in Aboriginal communities: a review of interventions. Darwin: Cooperative Research Centre for Aboriginal and Tropical Health, 2000.

[11] Dean M. Governmentality: power and rule in modern society. London: Sage Publications, 1999.

[12] Daly M. Sniffing at death. Advertiser, 29 December 1984, p. 21.
[13] Logan B. Deadly visions of the desert children. Sydney Morning Herald, 21 August 2000, p. 1.

[14] Logan B. Desert vision turns deadly. The Age, 22 August 2000, p. 13.

[15] Toohey P. A generation stolen by the fumes. Weekend Australian, 5-6 August 2000, p. 4.

[16] Squires N. Babies hooked on petrol fumes. Sunday Telegraph, 20 August 2000, p. 27.

[17] Kingdon J. Agendas, alternatives, and public policies, 2nd edn. New York: Harper Collins, 1995.

[18] Ministerial Council on Drug Strategy. National drug strategic framework 1998-99 to 2002-03. Canberra: Ministerial Council on Drug Strategy, Commonwealth of Australia, 1998.

[19] Commonwealth of Australia. National Action Plan on Illicit Drugs 2001 to 2002-2003. Canberra: Commonwealth Department of Health and Aged Care, 2001.

[20] Commonwealth of Australia. National action plan on illicit drugs 2001 to 2002-03: background paper. Canberra: Commonwealth Department of Health and Aged Care, 2001.

[21] Fitzgerald JL, Sewards T. Drug policy: the Australian approach. Canberra: Australian National Council on Drugs, 2002.

[22] Ministerial Council on Drug Strategy (MCDS). National Drug Strategy Aboriginal and Torres Strait Islander Peoples' Complementary Action Plan 2003-2006. Canberra: Commonwealth of Australia, 2003.

[23] National Campaign Against Drug Abuse. An Australian guide to drug issues. Canberra: Australian Government Publishing Service, 1986.

[24] National Aboriginal Health Strategy Working Party. A national Aboriginal health strategy. Canberra: National Aboriginal Health Strategy Working Party, 1989.

[25] National Campaign Against Drug Abuse. The National campaign against drug abuse 1985-88: evaluation and future directions. Monograph series no.12. Canberra: Australian Government Publishing Service, 1989.

[26] O'Malley P. Indigenous governance. In: Dean M, Hindess B, eds. Governing Australia: studies in contemporary rationalities of government. Cambridge, UK: Cambridge University Press, 1998:156-72.

[27] Cowlishaw G. Rednecks, eggheads and blackfellas: a study of racial power and intimacy in Australia. St Leonards, NSW: Allen and Unwin, 1999.

[28] Brady M. Heavy metal: the social meaning of petrol sniffing in Australia. Canberra: Aboriginal Studies Press, 1992.

[29] d'Abbs P, MacLean S. Petrol sniffing in Aboriginal communities: a review of interventions. Darwin, Northern Territory: Cooperative Research Centre for Aboriginal and Tropical Health, 2000.

[30] MacLean S, d'Abbs P. Petrol sniffing in Aboriginal communities: a review of interventions. Drug Alcohol Rev 2002;21:65-72.

[31] Lang E. Evaluation report on a programme to combat petrol sniffing in Aboriginal communities in Western Australia. Technical Report. Bentley, WA: National Centre for Research into the Prevention of Drug Abuse, Curtin University of Technology, 1989.

[32] Midford R, Rose J, Fleming D, Daly A. Glue: what's really in it for sniffers? [Letter]. Med J Aust 1993;159:634-5. 